\title{
Advertising, Brand Loyalty and Pricing
}

\author{
Ioana Chioveanu*
}

June 21, 2007

\begin{abstract}
I consider an oligopoly model where, prior to price competition, firms invest in persuasive advertising and induce brand loyalty in consumers who would otherwise buy the cheapest alternative on the market. This setting, in which persuasive advertising is introduced to homogenous product markets, provides an alternative explanation for price dispersion phenomena. Despite ex-ante symmetry, the equilibrium profile of advertising outlays is asymmetric. It follows that endogenously determined brand loyal consumer bases are not symmetric across firms. This raises a robustness question regarding Varian's "model of sales" where symmetry is exogenously assumed.
\end{abstract}

JEL: D21, D43, L11, L13, M37

Keywords: oligopoly, advertising, price dispersion, brand loyalty

\footnotetext{
*Economics Department, University of Alicante, San Vicente Campus, 03071, Alicante, Spain, email: ioana@merlin.fae.ua.es. I would like to thank Xavier Vives, as well as Ugur Akgun, Ramon Caminal, Xavier Martinez, Pierre Regibeau and Iestyn Williams. Financial support from IVIE is gratefully acknowledged. The paper benefited from the comments of participants at various conferences during 2003. Any remaining errors are mine.
} 


\section{Introduction}

Significant amounts of money are spent every year on advertising. The largest 100 advertisers in the US laid out a total of USD 90.31 billion on advertising in 2003 (see Advertising Age, June 28, 2004). Noticeably, in many advertising-intensive markets the products are nearly homogenous. This suggests that advertising could be used to redistribute buyers amongst sellers and not (only) to increase demand. Scherer and Ross (1990) note: "[d]ouble-blind experiments have repeatedly demonstrated that consumers cannot consistently distinguish premium from popular-priced beer brands, but exhibit definite preferences for the premium brands when labels are affixed-correctly or not". Although a vast literature spans the economics of advertising (see Bagwell, 2005), there are only a few theoretical models of persuasive advertising in non-differentiated good markets.

This article models homogenous product markets where persuasive advertising creates subjective product differentiation and changes the nature of subsequent price competition. In particular, it studies the strategic effect of persuasive advertising in a two-stage oligopoly model where firms compete in non-price advertising and prices. Advertising induces brand loyalty in consumers who would otherwise purchase the cheapest alternative on the market. Firms first invest in advertising, and then compete in prices for the remaining brand indifferent consumers. Despite a priori symmetry of the firms the advertising levels chosen by the firms are asymmetric in all subgame perfect equilibria of the two-stage game. One firm chooses a lower advertising level, while the other firms choose the same, higher level. In all pricing equilibria, at least two firms randomize on prices. The low advertiser prices more aggressively than the heavy advertisers in expected terms. The firms counterbalance their advertising and pricing decisions.

A related strand of literature deals with price dispersion phenomena in homogenous product markets. ${ }^{1}$ Varian (1980) constructs a "model of sales" where coexistence of fully informed and uninformed consumers results in equilibrium price dispersion. The uninformed (captured) consumers are evenly distributed across firms. The pricing stage in the current model is a modification of the model of sales, with asymmetric bases of captured consumers. In a variant of the model of sales, Rosenthal (1980) observes the existence of asymmetric pricing equilibria with at least two firms randomizing. Baye et al. (1992) fully characterize the asymmetric equilibria in the symmetric model of Varian. The current model builds up on a generalization of these results to asymmetric consumer bases. The two-stage game considered offers a way

\footnotetext{
${ }^{1}$ Baye et al. (forth.) review the literature on price dispersion in homogenous product markets, including clearinghouse models for virtual markets like Baye and Morgan (2001). The present setting also relates to online markets. With price-comparison sites, firms have incentives to engage (prior to price competition) in costly search-frustration activities, see Ellison and Ellison (2001).
} 
of endogenizing consumers' heterogeneity. It turns out that the symmetric outcome does not obtain, raising a robustness question regarding Varian's (1980) symmetric model.

The model offers a new perspective on the coexistence of price dispersion and advertising, taking a persuasive as opposed to an informative view of the latter. The advertising asymmetry prediction reconciles simple theoretical modelling with the empirical facts. Much empirical work explores whether homogenous goods advertising is informative (increases industry demand) or is persuasive (affects selective/brand demand). The results are often contradictory, and vary across industries. Kelton and Kelton (1982) and Baltagi and Levin (1986) support the persuasive view in US brewery and cigarette industries, respectively. ${ }^{2}$ Bagwell (2005) provides an up-todate review of both empirical and theoretical studies on advertising.

The persuasive view of advertising goes back to Kaldor (1950). Friedman (1983) and Schmalensee (1976) deal with oligopoly models where advertising increases selective demand. ${ }^{3}$ The latter explores the role of promotional competition in differentiated oligopoly markets where price changes are infrequent. In a model where advertising creates vertical differentiation, Sutton (1991) points out that differences in consumer tastes lead to the existence of two-tier markets. His study of the frozen-food industry illustrates the emergence of dual structures (where highadvertisers coexist with non-advertisers) in advertising-intensive markets. The current model also results in a two-tier structure.

A seminal article by Stigler (1961) reveals the role of price advertising in homogenous product markets. Butters (1977), Robert and Stahl (1993), McAfee (1994), and Roy (2000) link price dispersion models to informative advertising that targets consumers who face (possibly infinite) search costs. My model explores the use of non-price advertising in homogenous product markets. In a closely related paper, Baye and Morgan (2004) examine endogenous loyalty created by persuasive advertising, but through the lens of a model where price advertising decisions are also endogenized. ${ }^{4}$ Costly price advertising is at the heart of two major differences: Price dispersion persists even in the limit and, importantly, the equilibrium is symmetric. In contrast, ruling out price advertising and allowing for a more general persuasive advertising technology, the current model results in asymmetric advertising levels. This simple framework matches empirical findings.

\footnotetext{
${ }^{2}$ Lee and Tremblay (1992) find no evidence that advertising promotes beer consumption in the US. Nelson and Moran (1995) conclude that advertising serves to reallocate brand sales across alcoholic beverages.

${ }^{3}$ Von der Fehr and Stevik (1998) and Bloch and Manceau (1999) analyze the role of persuasive advertising in differentiated duopoly markets. Tremblay and Polasky (2002) show how persuasive advertising may affect price competition in a duopoly with no real product differentiation.

${ }^{4} \mathrm{I}$ am indebted to an anonymous referee for pointing out the relation with Baye and Morgan (2004) and for providing valuable intuition for the asymmetric advertising equilibrium.
} 
The key intuition for the emergence of asymmetric advertising equilibria is the following. At a potential symmetric profile of equilibrium advertising levels, the profit function of a firm has a kink. A unilateral deviation to a slightly higher advertising level does not alter a firm's profit which equals monopoly profit on its loyal base. To the contrary, a unilateral deviation to a slightly lower advertising level makes a firm's profit jump from its monopoly profits on the loyal base. By choosing a lower advertising level, the firm commits to be an aggressive player in the second stage. The discrete jump in its probability of winning the indifferent consumer base leads to an increase in its profits. As a result, the right and left derivatives of a firm's profit evaluated at a symmetric advertising profile cannot be simultaneously equal to zero. It follows that equilibrium advertising levels are asymmetric.

Section 2 describes the model, while section 3 presents the equilibrium in the pricing stage. Section 4 derives the equilibrium emerging in the advertising stage, and defines the outcome of the sequential game. Sections 5 and 6 discuss the setting and present some concluding remarks. All proofs missing from the text are relegated to the appendix.

\section{The Model}

There are $n$ firms selling a homogenous product. All firms have the same constant marginal cost. In the first period, firms choose simultaneously and independently their advertising expenditure levels and, in the second period, they compete in prices. Each firm promotes its product to induce subjective differentiation and brand loyalty. Let $\alpha_{i}$ be the advertising expenditure chosen by firm $i$. The fraction of consumers that are loyal to firm $i$ depends on the advertising expenditure profile. After the first stage, the advertising choices become common knowledge.

In the second stage, firm $i$ chooses the set of prices that are assigned positive density in equilibrium and the corresponding density function. The price charged by a firm is a draw from its price distribution. Let $F_{i}(p)$ be the distribution function of firm $i \in N=\{1,2, \ldots n\}$.

There is a continuum of consumers, with total measure 1 , who purchase one unit of the good whenever its price does not exceed a common reservation value $r$. Following advertising, some consumers remain indifferent between the alternatives (either because advertising did not reach them, or because it did not convince them) while the remainder become loyal to one brand or another. The indifferent consumers view the alternatives on the market as perfect substitutes and all purchase from the lowest price firm. The size of each group is determined by the total advertising investment in the market. The total number of loyal consumers, $U$, is assumed to be a strictly increasing and concave function of the aggregate advertising expenditure of the firms, 
$U=U\left(\Sigma_{i} \alpha_{i}\right)$, with $\lim _{\Sigma_{i} \alpha_{i} \rightarrow \infty} U\left(\Sigma_{i} \alpha_{i}\right)=1$. There is empirical evidence of diminishing returns to scale in advertising (Scherer and Ross, 1990; Bagwell, 2005). With higher advertising, more consumers join the captured (loyal) group. One may think that more advertising would be more convincing. The captured consumers are split amongst the firms according to a market sharing function depending on the advertising expenditures of the firms. ${ }^{5}$ Following Schmalensee (1976), let this fraction be $S_{i}\left(\alpha_{i}, \alpha_{-i}\right)=S_{i} \in[0,1]$, satisfying the following properties:

1. $\sum_{i=1}^{n} S_{i}=1$;

2. $\frac{\partial S_{i}}{\partial \alpha_{i}} \geq 0$ with strict inequality if $\exists j \neq i$ such that $\alpha_{j}>0$ or if $\alpha_{j}=0$, for all $j$;

3. $\frac{\partial S_{i}}{\partial \alpha_{j}} \leq 0$ with strict inequality if $\alpha_{i}>0$;

4. $S_{i}\left(\alpha_{i}, 0\right)=1$ if $\alpha_{i}>0$;

5. $S_{i}\left(0, \alpha_{-i}\right)=0$ if $\exists j \neq i$ such that $\alpha_{j}>0$ and $S(0,0)=0$;

6. $S_{i}\left(\alpha_{i}, \alpha_{-i}\right)$ is homogenous of degree 0 ;

7. $S_{i}\left(\alpha, \alpha_{-i}\right)=S_{j}\left(\alpha, \alpha_{-j}\right), \forall i, j \in N$, whenever $\alpha_{-j}$ is obtained from $\alpha_{-i}$ by permutation.

It follows from above that all loyal consumers are split amongst the firms with positive advertising levels (1,4 and 5). The market share of a firm increases in its own advertising, whenever it is below 1 , and decreases in rival advertising, whenever it is above 0 ( 2 and 3 ). The share profile remains unaffected by scaling all advertising by the same factor. Note that scaling up all advertising expenditures leads to an increase in the size of the loyal market, although firms' relative shares do not change. The market share of a firm depends on rivals' advertising levels and not on their identities. The market sharing function is symmetric across firms. An example of a market share function satisfying these conditions is $S\left(\alpha_{i}, \alpha_{-i}\right)=\frac{\alpha_{i}^{a}}{\Sigma_{j} \alpha_{j}^{a}}, a>0$.

Finally, the remaining consumers form the indifferent base, denominated by $I$. Hence, each firm faces the indifferent base $I=1-U\left(\Sigma_{i} \alpha_{i}\right)$ and a particular captured or locked-in base $U_{i}=S_{i}\left(\alpha_{i}, \alpha_{-i}\right) U\left(\Sigma_{i} \alpha_{i}\right)$. Firms cannot price discriminate between these two types of consumers.

The timing of the game can be justified by the fact that I deal with non-price advertising. Firms build-up a brand identity through advertising investment. A change in brand advertising takes time, whereas firms can modify their prices frequently. The subgame perfect Nash equilibrium is derived by solving backwards the two stage advertising-pricing game.

\footnotetext{
${ }^{5}$ I model captured consumers as a share of total loyals. Alternatively, one can directly define the loyal base of firm $i$ as $U_{i}\left(\alpha_{i}, \alpha_{-i}\right) \geq 0$, satisfying the appropriate assumptions. (See Section 4 for more details.) Then, $U=\sum_{i} U_{i}\left(\alpha_{i}, \alpha_{-i}\right)<1$ should hold.
} 


\section{The Pricing Stage}

In the first stage, firms simultaneously choose their advertising investments. In the second stage, knowing the whole profile of advertising outlays, firms choose prices. Without loss of generality, assume that the loyal bases satisfy $U_{i} \geq U_{j}$ whenever $i \leq j$ with $i, j \in N$. Firms compete for the brand switchers, $I=1-\Sigma_{i} U_{i}$. The tension between the incentives to undercut in order to win the indifferent market and those to extract surplus from the loyals leads to the non-existence of pure strategy equilibria. Baye, et al. (1992) prove this result and characterize all mixed strategy equilibria of the asymmetric game. ${ }^{6}$ Restricting attention to equilibria with convex supports, Proposition 1 directly follows from their analysis. For any firm $i \in N$, only the prices in the interval $A_{i}=\left[L_{i}, r\right]$ are relevant, with $L_{i}-c \geq \frac{(r-c) U_{i}}{I+U_{i}}$. Pricing at $p_{i}<L_{i}$, firms would make profits below minmax level and, pricing at $p_{i}>r$, firms would make zero profits. Let $L-c=\frac{(r-c) U_{n-1}}{I+U_{n-1}}$ and consider the functions $G(p)=1-\left[\frac{(r-p) U_{n-1}}{I(p-c)}\right]\left[\frac{L\left(I+U_{n}\right)}{I(p-c)}-\frac{U_{n}}{I}\right]^{\frac{1-m}{m}}$ and $H(p)=1-\left[\frac{(L-c)\left(I+U_{n}\right)}{I(p-c)}-\frac{U_{n}}{I}\right]^{\frac{1}{m}}$, where $m=|M|$ and $\emptyset \subset M \subseteq N \backslash\{n\}$. In Proposition 1, $M$ is the set of firms other than $n$ that randomize at equilibrium.

Proposition 1 If $U_{i} \geq U_{j}$ for $i \leq j$ and $M=\{n-1\}$, the following distribution functions represent a mixed strategy Nash equilibrium of the pricing subgame $\left(A_{i}, \pi_{i} ; i \in N\right)$ :

$$
\begin{aligned}
& F_{n}(p)=\left\{\begin{array}{l}
0 \text { for } p<L \\
G(p) \text { for } L \leq p<r \quad, F_{n-1}(p)=\left\{\begin{array}{l}
0 \text { for } p<L \\
H(p) \text { for } L \leq p<r \quad \text { and } \\
1 \text { for } p \geq r
\end{array} \text { for } p \geq r\right.
\end{array}\right. \\
& F_{k}(p)=\left\{\begin{array}{l}
0 \text { for } p<r \\
1 \text { for } p \geq r
\end{array} \text { for } \forall k<n-1 .\right.
\end{aligned}
$$

If firms employ convex supports, this is the unique equilibrium that applies to any weakly ordered profile of loyal bases. If $U_{i}=\bar{U}$ for $i \leq n-1, U_{n}<\bar{U}$, and $|M| \geq 2$, then $F_{n}(p), F_{j}(p)=$ $F_{n-1}(p)$ for $j \in M$ and $F_{k}(p)$ for $k \in N \backslash\{\{n\} \cup M\}$, are a family of pricing equilibria with more than two firms randomizing.

Proposition 1 presents multiple equilibria for specific advertising profiles. However, for any such profile all equilibria are outcome-equivalent, i.e. the profits of the firms are invariant across the equilibria.

\footnotetext{
${ }^{6}$ Klemperer (1987) notes the emergence of mixed strategy equilibria when consumers with zero and positive switching costs coexist.
} 
Proposition 2 Let $U_{i} \geq U_{j}$ whenever $i \leq j$ and $I=1-\Sigma_{i} U_{i}, i, j \in N$. The expected profits (gross of advertising outlays) in all second stage Nash equilibria are:

$$
E \pi_{j}=(r-c) U_{j}, \quad \forall j \in N \backslash\{n\} \text { and } E \pi_{n}=(L-c)\left(U_{n}+I\right)=(r-c) V_{n},
$$

where $V_{n}=U_{n-1}\left(\frac{U_{n}+I}{U_{n-1}+I}\right)$.

In all second stage equilibria at least two firms randomize on prices. In one limiting equilibrium, all other firms choose monopoly pricing. This is the unique equilibrium that applies to any arbitrary profile of loyal bases. This equilibrium predicts significant price dispersion in relatively small markets. The higher the number of competitors, the lower the chances of an individual firm to win the indifferent market. When concentration decreases, more firms prefer to rely on their locked-in markets and act as monopolists rather than engage in aggressive pricing. Narasimhan (1988) derived the pricing equilibrium in a model where two firms count on loyal consumer bases and compete for brand switchers. In that context, pricing below the monopoly level with positive probability is viewed as a price promotion. His model links price dispersion in competitive markets to consumer switching. This section extends his setting to oligopoly, when the switchers are extremely price sensitive. This limiting equilibrium points out the inadequacy of this type of model in explaining market-wide price promotions in larger oligopolies.

Baye and Morgan (2004) use a model where there are cross effects between price and brand advertising. In contrast to Varian (1980) and the current model, they show that even in the limit (when the number of firms is large) price dispersion persists. At equilibrium, costly price advertising may occur only if a finite number of firms post ads. Then, at least some firms count on (non-vanishing) loyal bases even in the limit.

When $U_{i}=\bar{U}$ for $i \leq n-1$ and $U_{n} \leq \bar{U}$, there exists another limiting pricing equilibrium with all firms randomizing over the same convex support. In all equilibria, if $U_{n}<U_{n-1}$, then firm $n$ randomizes differently. It prices more aggressively in order to increase its chances of winning the indifferent consumers. This allows to partially offset its loyal base disadvantage.

In his symmetric setting, Rosenthal (1980) points out that a decrease in market concentration leads to a higher price. Stahl (1989) obtains the same result with endogenous information acquisition, which is costless for a fraction of the consumers referred to as shoppers, and costly for the others. As the number of firms increases, the firms compete for the same number of shoppers and the incentives to undercut prices are lower. The pricing stage of the current model supports Rosenthal's finding in a more general asymmetric setting. It is however important to note that here the total market size is fixed and the positive concentration-price relationship 
does not necessarily hold as the size of both the indifferent consumer group and the loyal base of each firm are endogenously determined. In Rosenthal (1980), an increase in the number of firms does not alter the number of indifferent consumers and it brings in equally sized loyal groups attached to the entrants.

Extending the "model of sales", Baye, et al. (1992) construct a metagame in which consumers are also players. In the first stage, uninformed consumers and firms move simultaneously. Firms choose a price distribution and the uninformed consumers decide where to purchase. In the second stage, the informed consumers choose an outlet. Given that the asymmetric price distributions can be ranked by first-order stochastic dominance, they show that the unique subgame perfect equilibrium of the extensive game is the symmetric one. This follows from the equilibrium consistency requirement that a firm with higher expected price cannot have a larger uninformed consumer base. In my model, only firms make decisions, and the subgame perfect equilibria of the game are asymmetric. The next section proves this result.

\section{Advertising Expenditure Choices}

In this section, I derive the equilibrium of the reduced form game where the oligopolists simultaneously choose an advertising expenditure. Their payoffs are the profits emerging in the pricing stage minus the advertising expenditure. Profits gross of advertising cost are given in Proposition 2. Note that $V_{n}=U_{n}$ if $U_{n}=U_{n-1}$.

The loyal consumer group of firm $i\left(U_{i}\right)$ is given by $U_{i}\left(\alpha_{i}, \alpha_{-i}\right)=S_{i}\left(\alpha_{i}, \alpha_{-i}\right) U\left(\Sigma_{j} \alpha_{j}\right)$. The consumers who are not persuaded (or reached) by advertising form the brand indifferent group $\left(I=1-\sum_{i=1}^{n} U_{i}\left(\alpha_{i}, \alpha_{-i}\right)=1-U\left(\Sigma_{i} \alpha_{i}\right)\right)$ which buys the cheapest product. Under the assumptions made so far, the size of the loyal group of a firm increases with that firm's advertising. The incremental consumers may derive from the brand indifferent group $\left(U^{\prime}\left(\Sigma_{i} \alpha_{i}\right)>0\right)$ or from rivals' loyal groups $\left(\frac{\partial S_{i}\left(\alpha_{i}, \alpha_{-i}\right)}{\partial \alpha_{i}} \geq 0\right)$. The latter allows for reciprocal cancellation of advertising across brands. See Bagwell (2005) for empirical evidence on this issue. An increase in rival advertising has two conflicting effects on the loyal base of a firm. There is a positive effect due to the increase in the total number of loyal consumers $\left(U^{\prime}\left(\Sigma_{i} \alpha_{i}\right)>0\right)$ and a negative one due to a decrease in the firm's share of loyal consumers $\left(\frac{\partial S_{i}\left(\alpha_{i}, \alpha_{-i}\right)}{\partial \alpha_{j}} \leq 0\right)$. I assume that the overall effect of rival advertising is negative.

A1: $\frac{\partial^{2} U_{i}}{\partial \alpha_{i}^{2}}<0, \frac{\partial^{2} U_{i}}{\partial \alpha_{i}^{2}} \leq \frac{\partial^{2} U_{i}}{\partial \alpha_{i} \partial \alpha_{j}}$ for $i, j<n$ and $\frac{\partial^{2} V_{n}}{\partial \alpha_{n}^{2}}<0$ and $\frac{\partial U_{i}}{\partial \alpha_{i}}(0,0)>\frac{1}{r-c}$.

A2: $\frac{\partial^{2} U_{i}}{\partial \alpha_{i} \partial \alpha_{j}} \leq 0, \frac{\partial^{2} V_{n}}{\partial \alpha_{n} \partial \alpha_{j}} \leq 0$.

Assumptions A1 and A2 guarantee the existence of equilibrium. 
With $\alpha_{n} \leq \alpha_{n-1} \leq \ldots \leq \alpha_{1}$, firm $j \neq n$ maximizes its profit net of advertising expenditure:

$$
\pi_{j}=(r-c) S_{j} U\left(\Sigma_{i} \alpha_{i}\right)-\alpha_{j}=\pi^{H}
$$

Firm $n$ maximizes its expected profit net of advertising costs:

$$
\pi_{n}=(r-c) S_{n-1} U\left(\Sigma_{i} \alpha_{i}\right) \frac{\left(S_{n} U\left(\Sigma_{i} \alpha_{i}\right)+I\right)}{\left(S_{n-1} U\left(\Sigma_{i} \alpha_{i}\right)+I\right)}-\alpha_{n}=\pi^{L} .
$$

Notice that $\pi^{H}=\pi^{L}$ when $\alpha_{n}=\alpha_{n-1}$. The FOC of the maximization problems above implicitly define $\alpha_{n}^{*}\left(\alpha_{-n}\right)$ and $\alpha_{j}^{*}\left(\alpha_{-j}\right)$ for $j \in N \backslash\{n\}$. For a symmetric equilibrium $\alpha^{*}$ to exist, firm $n$ should not have incentives to decrease its advertising from $\alpha_{n}^{*}$, while the other firms should not have incentives to increase, their advertising from $\alpha_{j}^{*}$.

$$
\frac{\partial \pi_{n}}{\partial \alpha_{n}}\left(\alpha^{*}, \alpha_{-n}^{*}\right) \geq 0 \text { and } \frac{\partial \pi_{j}}{\partial \alpha_{j}}\left(\alpha^{*}, \alpha_{-j}^{*}\right) \leq 0 \text { for all } j \in N \backslash\{n\} .
$$

In the appendix I show that this requirement leads to a contradiction. Together with the optimization problem above, this proves the following result.

Proposition 3 Under A1, in any pure strategy Nash equilibrium of the reduced form advertising game, $\alpha_{n}<\alpha_{i}=\alpha_{j}$ for $\forall i, j \in N \backslash\{n\}$. The values of $\alpha_{n}$ and $\alpha_{i}(\forall i \in N \backslash\{n\})$ are implicitly defined by the FOCs.

The following example illustrates that a symmetric advertising profile cannot form part of an equilibrium.

Example 1 Let $S_{i}\left(\alpha_{i}, \alpha_{-i}\right)=\frac{\alpha_{i}}{\Sigma_{j} \alpha_{j}}$ for $\forall i \in N, U\left(\Sigma_{j} \alpha_{j}\right)=\frac{\Sigma_{j} \alpha_{j}}{1+\Sigma_{j} \alpha_{j}}, n=2, r>1$ and $c=0 .^{7}$ Then at $\alpha_{1}=\alpha_{2}=\alpha$, the symmetric payoffs are given by $\pi_{1}^{S}=\pi_{2}^{S}=r \frac{\alpha}{1+2 \alpha}-\alpha$. For $r<\left(\frac{1+2 \alpha}{\alpha}\right)^{2}(1+\alpha)$, firm 1 has incentives to deviate to $\alpha_{1}^{L}=\alpha \sqrt{\frac{r}{1+\alpha}}-(1+\alpha)<\alpha$. For $r \geq\left(\frac{1+2 \alpha}{\alpha}\right)^{2}(1+\alpha)$, firm 1 has incentives to deviate to $\alpha_{1}^{H}=\sqrt{r(1+\alpha)}-(1+\alpha)>\alpha .{ }^{8}$

A1 requires that $\frac{\partial^{2} U_{i}}{\partial \alpha_{i}^{2}} \leq \frac{\partial^{2} U_{i}}{\partial \alpha_{i} \partial \alpha_{j}}$. This guarantees that, given $\alpha_{n}$, firms $i, j \in N \backslash\{n\}$ choose $\alpha_{i}=\alpha_{j}$ at equilibrium (see Vives, 1999) and allows the equilibrium outcome to be fully defined. Without this restriction, more general asymmetries may arise at equilibrium. However, $\alpha_{n}<\alpha_{i}$ for $\forall i \in N \backslash\{n\}$ in any reduced form game equilibrium.

\footnotetext{
${ }^{7}$ The sharing rule in the example, $S_{i}\left(\alpha_{i}, \alpha_{-i}\right)=\frac{\alpha_{i}}{\Sigma_{j} \alpha_{j}}$ might be interpreted as the probability that an arbitrary loyal consumer chooses firm $i$. This probability is nonincreasing in $i$ and thus a firm with higher advertising is more likely to be chosen by a loyal consumer.

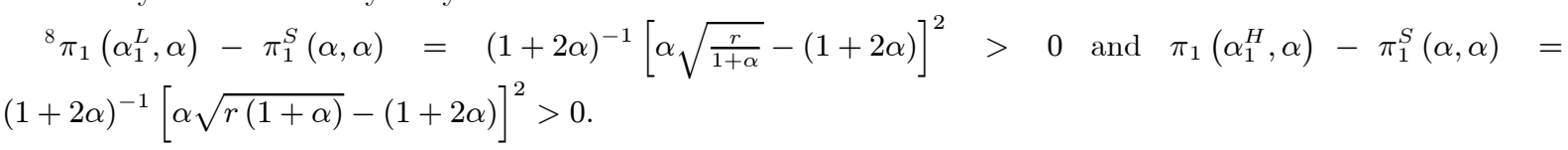


Proposition 4 Under A1 and A2, the advertising outlays in Proposition 3, together with any of the pricing strategy profiles in Proposition 1 give the subgame perfect equilibria of the two stage game.

To see the role played by submodularity (A2), consider a duopoly. Let $\left(\alpha_{1}, \alpha_{2}\right)$ with $\alpha_{1}>\alpha_{2}$ be a candidate equilibrium. As $\frac{\partial \pi_{H}}{\partial \alpha_{H}}\left(\alpha_{1}, \alpha_{2}\right)=0$, if firm 2 deviates to $\alpha \geq \alpha_{1}$ its profits fall. For $\forall \alpha \geq \alpha_{1}$, its marginal profit is $\frac{\partial \pi_{H}}{\partial \alpha_{H}}\left(\alpha, \alpha_{1}\right)<\frac{\partial \pi_{H}}{\partial \alpha_{H}}\left(\alpha_{1}, \alpha_{1}\right) \leq \frac{\partial \pi_{H}}{\partial \alpha_{H}}\left(\alpha_{1}, \alpha_{2}\right)=0$. The first inequality follows from strict concavity and the second from submodularity. Then $\pi_{H}\left(\alpha, \alpha_{1}\right)<\pi_{H}\left(\alpha_{1}, \alpha_{1}\right)=\pi_{L}\left(\alpha_{1}, \alpha_{1}\right) \leq \pi_{L}\left(\alpha_{2}, \alpha_{1}\right)$. A symmetric argument can be used to show that firm 1 does not have an incentive to deviate to $\alpha \leq \alpha_{2}$. A general proof for an arbitrary number of firms is provided in the Appendix. However, A2 is sufficient but not necessary for an asymmetric equilibrium to exist. This can be easily seen in Example 1 . For $r-c=16$, the candidate equilibrium is $\left(\alpha_{1}, \alpha_{2}\right)=(3.94,2.15)$. Firm 1 does not have incentives to leapfrog firm 2 : its profits on $[0,2.15]$ are maximized at 1.7 , and $\pi_{1}(1.7,2.15)=$ $4.38<\pi_{1}(3.94,2.15)=4.95$. Firm 2 does not have incentives to leapfrog firm 1: its profits on $[3.94, \infty)$ are maximized at 3.95 , and $\pi_{2}(3.95,3.94)=3.15<\pi_{2}(2.15,3.94)=3.52$. The best response graph is presented in the Appendix. ${ }^{9}$

Other models that yield such asymmetric equilibria can be found in McAffee (1994) and Amir and Wooders (2000). In these models (as in the present one), payoff functions are submodular and best response functions jump down over the diagonal in a $n-1$ symmetric best response mapping.

The asymmetric equilibrium follows from the fact that firms weigh their first and second stage decisions. A larger first stage investment triggers less aggressive second stage pricing, while a lower investment supposes a more aggressive pricing strategy. Although they are initially identical, at equilibrium, firms choose asymmetric advertising outlays. This asymmetry is linked to the choice of mixed pricing strategies. There is one firm with a strictly lower advertising level (firm $n$ in the example) and with the lowest loyal group. All other firms choose the same higher level of advertising and have equal larger loyal consumer bases. In Example 1, the low advertiser makes profits net of advertising cost lower than its rival, but this may not be true in general. The firm with the smallest loyal group prices more aggressively, has highest probability of being the winner of the indifferent market, and makes the lowest gross expected profits. All other firms price less aggressive and all make profits gross of advertising expenditure that are equal to the monopoly profit on their loyal market.

\footnotetext{
${ }^{9}$ I use Example 1 for computational convenience. Though well defined, it satisfies A1, but not A2. An example satisfying both A1 and A2 for $n=2$ is $S_{i}\left(\alpha_{i}, \alpha_{-i}\right)=\frac{\alpha_{i}^{1 / 6}}{\Sigma_{i} \alpha_{i}^{1 / 6}}$ for $\forall i \in N, U\left(\Sigma_{i} \alpha_{i}\right)=\frac{\Sigma_{i} \alpha_{i}^{1 / 6}}{1+\Sigma_{i} \alpha_{i}^{1 / 6}}$.
} 
In the remainder of this section I offer a possible microfoundation for the demand system considered. It applies to the case of a duopoly. A random utility model can lead to the proportional market sharing function $S_{i}=\frac{\alpha_{i}}{\Sigma_{j} \alpha_{j}}$ used in the examples, when consumers respond to advertising and prices, but are short-sighted. With a duopoly there is a unique mixed pricing equilibrium where both firms randomize, and $E\left(p_{i} \mid p_{i}<r\right)=E\left(p_{j} \mid p_{j}<r\right)$, where $p_{i}$ is the price of firm $i$. In the marketing literature, price dispersion models are used to explain price promotions. The expected price conditional on a brand being priced below $r$ is interpreted as the average discounted price, while $1-F(r)$ measures the frequency of discounts. Assuming that loyal consumers are myopic and care only about the average discount and advertising, the proportional market sharing function, $S_{i}=\frac{\alpha_{i}}{\Sigma_{j} \alpha_{j}}$, can be derived from a random utility model. ${ }^{10}$

\section{Discussion}

While there is no doubt that advertising plays an important informative role in the economy, occasions in which it does not provide any relevant information on price or product characteristics are not less relevant. In many homogenous product markets, advertising only serves to redistribute consumers among the sellers. Many advertising campaigns have rather an emotional content and try to attract consumers by associating the product with attitudes or feelings that have no relevant relationship to the product or its consumption. Commenting on Chevrolet's 1988 "Heartbeat of America" TV ads for automobiles, G.M.'s advertising executive Sean Fitzpatrick observed that they "may look disorganized, but every detail is cold-heartedly calculated. People see the scenes they want to identify with. [...] It's not verbal. It's not rational. It's emotional, just the way people buy cars" (see Scherer and Ross 1990 p. 573, originally from "On the Road again, with a Passion", New York Times October 10th, 1988.) Referring to the new trends in television advertising, James Twitchell, Professor of advertising at the University of Florida, noted that "Advertising is becoming art. You don't need it, but it's fun to look at" (see Herald Tribune, January 10, 2003, p. 7). Loewenstein (2001) remarks "[w]hile conventional models of decision making can make sense of advertisements that provide information about products (whether informative or misleading), much advertising- for example, depicting happy, attractive friends drinking Coca-Cola seem to have little informational content. Instead such advertising seems to be intended to create mental associations that operate in both directions, causing one to think that one should be drinking Coca-Cola if one is with friends (by evoking a choice heuristic) and to infer one that one must be having fun if one is drinking Coca-Cola (playing on

\footnotetext{
${ }^{10}$ Consumers have idiosyncratic preferences over the brands and each consumer chooses the one that has the greatest brand advertising-average discounted price differential (see Anderson et al. (1992)).
} 
the difficulty of evaluating one's hedonic state)." See also Camerer et al. (forthcoming).

Persuasive advertising could be a way to influence such categorization through mental associations. Pepsi's 1997 GeneratioNext campaign defines itself as being "about everything that is young and fresh, a celebration of the creative spirit. It is about the kind of attitude that challenges the norm with new ideas, at every step of the way". Perrier significantly strengthened its position in the French mineral water market with its advertising campaign directed at the younger generation, under the slogan "Perrier c'est fou" ("Perrier is crazy"). This created a perception of the product as being very fashionable (see Sutton, 1991). Even more relevant is the subsequent Perrier campaign under the meaningless slogan "Ferrier c'est pou". These considerations support the persuasive view of advertising and offer a justification for the stylized setting considered here.

The present analysis suggests that high advertisers tend to have higher prices. Often, blind tests show that consumers perceive highly advertised brands as different. The model also predicts the existence of a group of heavy advertisers and of a low advertiser. This is consistent with the empirical evidence that markets with significant advertising have a two-tier structure.

Several extensions to this work are worth mentioning. A major limitation of the present model is the extreme post-advertising heterogeneity of consumers: loyal consumers are extremely responsive to advertising, while the indifferent ones continue to be extremely price sensitive. One may consider a smoother distribution of advertising-induced switching costs. Moreover, indifferent consumers are assumed to be aware about the existence of all products. Perhaps it is more realistic to assume that the indifferent consumers know only the prices of some sellers.

\section{Conclusions}

The present article proposes a way to model the effects of persuasive advertising on price competition in a homogenous product market. In a two stage game, an oligopoly first invests in persuasive advertising and, then, competes in prices. Advertising results in the creation of loyal consumer groups attached to the firms. The model predicts asymmetric advertising outlays despite the initial symmetry of firms. This finding matches the empirical evidence in advertising intensive markets. The setting shows how persuasive advertising may be used to relax price competition, and links it to equilibrium price dispersion. 


\section{Appendix}

Proof of Proposition 3. Suppose to the contrary that there exists an advertising equilibrium, $\alpha^{*}=\left(\alpha_{1}^{*}, \ldots \alpha_{n}^{*}\right)$ with the two lowest advertising outlays equal $\left(\alpha_{n-1}^{*}=\alpha_{n}^{*}\right)$. By assumption A1, $\exists \alpha_{i}^{*}>0$ for some $i$. Consider first $\alpha_{n-1}^{*}=\alpha_{n}^{*}>0$. Then, the marginal profit for a downward deviation of firm $n$ and an upward deviation of firm $n-1$ should be both equal to zero. Considering the profit expressions in Proposition 2 and letting $U_{n-1}\left(\alpha^{*}\right)=U_{n}\left(\alpha^{*}\right)=\bar{U}$, the marginal profits corresponding to these deviations are given by:

$$
\begin{gathered}
\frac{\partial \pi_{n-1}}{\partial \alpha_{n-1}}\left(\alpha^{*}\right)=(r-c) \frac{\partial U_{n-1}}{\partial \alpha_{n-1}}\left(\alpha^{*}\right)-1 \text { and } \\
\frac{\partial \pi_{n}}{\partial \alpha_{n}}\left(\alpha^{*}\right)=(r-c)\left(\frac{\partial U_{n-1}}{\partial \alpha_{n}}\left(\alpha^{*}\right)+\bar{U} \frac{\frac{\partial U_{n}}{\partial \alpha_{n}}\left(\alpha^{*}\right)-\frac{\partial U_{n-1}}{\partial \alpha_{n}}\left(\alpha^{*}\right)}{\bar{U}+1-U\left(\alpha^{*}\right)}\right)-1 .
\end{gathered}
$$

Notice that $\frac{\partial U_{n-1}}{\partial \alpha_{n-1}}\left(\alpha^{*}\right)=\frac{\partial U_{n}}{\partial \alpha_{n}}\left(\alpha^{*}\right)$.

Then, $\frac{\partial \pi_{n-1}}{\partial \alpha_{n-1}}\left(\alpha^{*}\right)-\frac{\partial \pi_{n}}{\partial \alpha_{n}}\left(\alpha^{*}\right)=(r-c)\left(\frac{\partial U_{n-1}}{\partial \alpha_{n-1}}\left(\alpha^{*}\right)-\frac{\partial U_{n-1}}{\partial \alpha_{n}}\left(\alpha^{*}\right)\right)\left(\frac{1-U\left(\alpha^{*}\right)}{\bar{U}+1-U\left(\alpha^{*}\right)}\right)$.

Since $\alpha_{n}^{*}>0$, it follows that $\frac{\partial U_{n-1}}{\partial \alpha_{n-1}}\left(\alpha^{*}\right)>0$ and $\frac{\partial U_{n-1}}{\partial \alpha_{n}}\left(\alpha^{*}\right)<0$. Also $U\left(\alpha^{*}\right)<1$, and a contradiction is obtained as $\frac{\partial \pi_{n-1}}{\partial \alpha_{n-1}}\left(\alpha^{*}\right)>\frac{\partial \pi_{n}}{\partial \alpha_{n}}\left(\alpha^{*}\right)$.

It follows that $\alpha_{n}^{*}<\alpha_{n-1}^{*}$ in any equilibrium where $\alpha_{n}^{*}>0$.

Next consider $\alpha_{n-1}^{*}=\alpha_{n}^{*}=0$. Then, it must hold that $\frac{\partial \pi_{n-1}}{\partial \alpha_{n-1}}\left(\alpha^{*}\right) \leq 0$. Recall that by A1, $\frac{\partial^{2} U_{i}}{\partial \alpha_{i}^{2}}<0$ and $\frac{\partial^{2} U_{i}}{\partial \alpha_{i}^{2}} \leq \frac{\partial^{2} U_{i}}{\partial \alpha_{i} \partial \alpha_{j}}$. As $\alpha_{i}^{*}>0=\alpha_{n-1}^{*}$, it follows that $\frac{\partial \pi_{i}}{\partial \alpha_{i}}\left(\alpha^{*}\right)<\frac{\partial \pi_{n-1}}{\partial \alpha_{n-1}}\left(\alpha^{*}\right) \leq 0$. But, then $\alpha_{i}^{*}=0$. A contradiction. I conclude that $\alpha_{n}^{*}<\alpha_{n-1}^{*}$ in equilibrium.

Finally, consider $i<j<n$, the FOC imply $\frac{\partial U_{i}}{\partial \alpha_{i}}-\frac{1}{r-c}=0$ and $\frac{\partial U_{j}}{\partial \alpha_{j}}-\frac{1}{r-c}=0$. By A1 $\alpha_{i}>\alpha_{j}$ implies $\frac{\partial U_{i}}{\partial \alpha_{i}}<\frac{\partial U_{j}}{\partial \alpha_{j}}$. Since $\alpha_{i} \geq \alpha_{j}$, it follows that $\alpha_{i}=\alpha_{j}$ should hold for $i, j \neq n$. This establishes that $\alpha_{n}<\alpha_{n-1}=\ldots=\alpha_{1}$ in equilibrium.

Proof of Proposition 4. To make sure that the candidate maximum defines the first stage strategies in a subgame perfect equilibrium, firm $j=1, \ldots n-1$ should not have incentives to leapfrog firm $n$, and firm $n$ should not have incentives to leapfrog its rivals.

Let $\alpha_{i}^{*}$ be the equilibrium choice of firm $i \in N \backslash\{n\}, \alpha_{n}^{*}$ be the equilibrium choice of firm $n$ and $\bar{\alpha}^{*} \in R^{n-2}$ be the vector of equilibrium choices if firms $j \in N \backslash\{i, n\} . \quad \pi_{i, 1}$ is the own partial derivative of firm $i$ 's profit function.

Consider firm $n$. Its profits are:

$\pi_{n}\left(\alpha, \alpha_{i}^{*}, \bar{\alpha}^{*}\right)=\left\{\begin{array}{cc}(r-c) V_{n}\left(\alpha, \alpha_{i}^{*}, \bar{\alpha}^{*}\right)-\alpha=\pi_{n}^{L}\left(\alpha, \alpha_{i}^{*}, \bar{\alpha}^{*}\right) & \text { if } \alpha \leq \alpha_{i}^{*} \\ (r-c) U_{n}\left(\alpha, \alpha_{i}^{*}, \bar{\alpha}^{*}\right)-\alpha=\pi_{n}^{H}\left(\alpha, \alpha_{i}^{*}, \bar{\alpha}^{*}\right) & \text { if } \alpha>\alpha_{i}^{*}\end{array}\right.$,

where $\alpha$ is the choice of firm $n$.

Consider the case $\alpha>\alpha_{i}^{*}$, then the following is true:

$0=\pi_{n, 1}^{H}\left(\alpha_{i}^{*}, \alpha_{n}^{*}, \bar{\alpha}^{*}\right)>\pi_{n, 1}^{H}\left(\alpha, \alpha_{n}^{*}, \bar{\alpha}^{*}\right) \geq \pi_{n, 1}^{H}\left(\alpha, \alpha_{i}^{*}, \bar{\alpha}^{*}\right)$. The first inequality follows from strict 
concavity (A1) and the second from submodularity of $U_{n}(\mathrm{~A} 2)$. Then, firm $n$ has incentives to decrease.

When $\alpha \leq \alpha_{i}^{*}$, the profit function is concave and, hence, maximized at $\alpha=\alpha_{n}^{*}$.

Consider firm $j \in N \backslash\{n\}$. Its profits are:

$\pi_{j}\left(\alpha, \alpha_{n}^{*}, \bar{\alpha}^{*}\right)=\left\{\begin{array}{cc}(r-c) U_{j}\left(\alpha, \alpha_{n}^{*}, \bar{\alpha}^{*}\right)-\alpha=\pi_{j}^{H}\left(\alpha, \alpha_{n}^{*}, \bar{\alpha}^{*}\right) & \text { if } \alpha \geq \alpha_{n}^{*} \\ (r-c) V_{j}\left(\alpha, \alpha_{n}^{*}, \bar{\alpha}^{*}\right)-\alpha=\pi_{j}^{L}\left(\alpha, \alpha_{n}^{*}, \bar{\alpha}^{*}\right) & \text { if } \alpha<\alpha_{n}^{*}\end{array}\right.$,

where $V_{j}\left(\alpha, \alpha_{n}^{*}, \bar{\alpha}^{*}\right)=U_{n}\left(\alpha_{n}^{*}, \alpha, \bar{\alpha}^{*}\right) \frac{U_{j}\left(\alpha, \alpha_{n}^{*}, \bar{\alpha}^{*}\right)+I}{U_{n}\left(\alpha_{n}^{*}, \alpha, \bar{\alpha}^{*}\right)+I}$ and $\alpha$ is the choice of firm $j$.

Consider $\alpha<\alpha_{n}^{*}$, then the following is true:

$0=\pi_{j, 1}^{L}\left(\alpha_{n}^{*}, \alpha_{i}^{*}, \bar{\alpha}^{*}\right)<\pi_{j, 1}^{L}\left(\alpha, \alpha_{i}^{*}, \bar{\alpha}^{*}\right) \leq \pi_{j, 1}^{L}\left(\alpha, \alpha_{n}^{*}, \bar{\alpha}^{*}\right)$.

The first inequality follows from strict concavity (A1) and the second from submodularity of $V_{j}$ (A2). Then, firm $j$ has incentives to increase. When $\alpha \geq \alpha_{n}^{*}$, the profit function is strictly concave and, hence, maximized at $\alpha=\alpha_{j}^{*}$.

Example 1 Best response functions for $r-c=16$.

Given rival's choice $\alpha$, firm $i$ 's best response would be $\alpha_{i}^{H}(\alpha)=4(1+\alpha)^{\frac{1}{2}}-(1+\alpha)$ if it chose $\alpha_{i} \geq \alpha$ and would be $\alpha_{i}^{L}(\alpha)=4 \alpha(1+\alpha)^{-\frac{1}{2}}-(1+\alpha)$ if it chose $\alpha_{i}<\alpha$.

The corresponding profits are:

$\pi_{i}(\alpha)=\left\{\begin{array}{c}\pi_{i}^{H}(\alpha)=16-8(1+\alpha)^{\frac{1}{2}}+(1+\alpha) \text { for } \alpha_{i} \geq \alpha \\ \pi_{i}^{L}(\alpha)=16 \alpha(1+\alpha)^{-1}-8 \alpha(1+\alpha)^{-\frac{1}{2}}+(1+\alpha) \text { for } \alpha_{i}<\alpha\end{array}\right.$.

Since $\pi_{i}^{H}(\alpha) \geq \pi_{i}^{L}(\alpha) \Leftrightarrow \alpha \leq 3$, the best response of firm $i$ is $\alpha_{i}(\alpha)=\left\{\begin{array}{l}\alpha_{i}^{H}(\alpha) \text { for } \alpha \leq 3 \\ \alpha_{i}^{L}(\alpha) \text { for } \alpha>3\end{array}\right.$ and it has a jump down at $\alpha=3$.

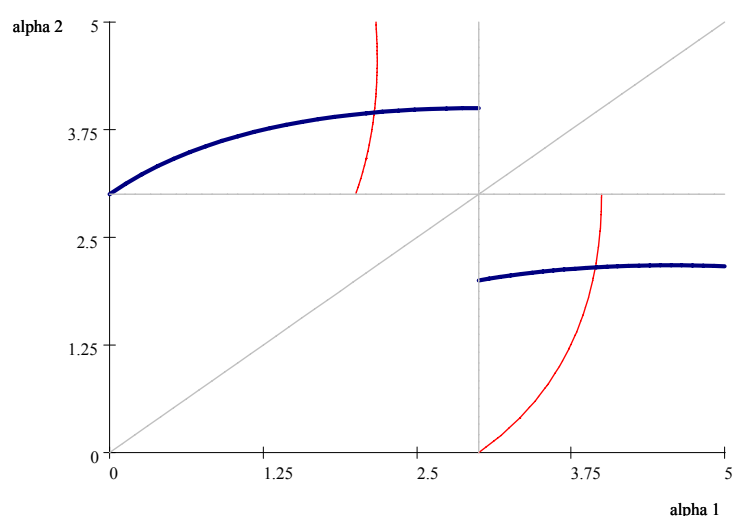

Figure 1: Best response functions in Example 1 for $r-c=16$. 


\section{References}

Advertising Age, June 28, 2004. 100 Leading National Advertisers.

Amir, R. , Wooders J., 2000. One-way spillovers, endogenous innovator/imitator roles and research joint ventures. Games Econ. Behav. 31, 1-25.

Anderson, S., De Palma, A., Thisse, J.-F., 1992. Discrete Choice Theory of Product Differentiation. MIT Press, Cambridge.

Baltagi, B. H., Levin, D., 1986. Estimating dynamic demand for cigarettes using panel data: the effects of bootlegging, taxation and advertising reconsidered. Rev. Econ. Statist. 68, 148-155.

Bagwell, K., 2005. The Economic Analysis of Advertising. Forthcoming in: Armstrong, M. , Porter, R. (Eds.), Handbook of Industrial Organization. North-Holland, Amsterdam.

Baye, M., Kovenock, D., de Vries, C., 1992. It takes two to tango: equilibria in a model of sales. Games Econ. Behav. 4, 493-510.

Baye, M., Morgan, J., 2001. Information gatekeepers on the internet and the competitiveness of homogenous product markets. Amer. Econ. Rev 91, 454-474.

Baye, M., Morgan, J., Scholten, P. Information, search and price dispersion. Forthcoming in Hendershott, T. (Ed.), Handbook of Economics and Information Systems. Elsevier Press.

Baye, M., Morgan, J., 2004. Brand and price advertising in online markets. Mimeo.

Bloch, F., Manceau, D., 1999. Persuasive advertising in Hotelling's model of product differentiation. Int. J. Ind. Organ. 17, 557-574.

Butters, G., 1977. Equilibrium distributions of sales and advertising prices. Rev. Econ. Stud. 44, 465-491.

Camerer C. , Loewenstein G. , Prelec D. , Forthcoming. Neuroeconomics: how neuroscience can inform economics. J. Econ. Lit.

Ellison, G., Fisher Ellison, S., 2004. Search, obfuscation, and price elasticities on the internet. NBER Working Papers 10570.

Friedman, J., 1983. Oligopoly Theory. Cambridge University Press.

Herald Tribune, January 10th, 2003. As viewers zap ads, TV hatches an old plan p. 1/7.

Kaldor N.V., 1950. The economic aspects of advertising. Rev. Econ. Stud. 18, 1-27.

Kelton, C., Kelton, D. 1982. Advertising and intraindustry brand shift in the U.S. brewing industry.

J. Ind. Econ. 30, 293-303.

Klemperer P., 1987. Markets with consumer switching costs. Quart. J. Econ. 102, 375-393.

Lee, B., Tremblay V., 1992. Advertising and the US demand for beer. Appl. Econ. 24, 69-76. 
Loewenstein G. , 2001. The creative destruction of decision research. J. Cons. Res. 28(3), 499-505.

McAfee, P. , 1994. Endogenous availability, cartels, and merger in an equilibrium price dispersion. J. Econ. Theory 62, 24-47.

Narasimhan, C., 1988. Competitive promotional strategies. J. Bus. 61, 427-449.

Nelson, J., Moran, J., 1995. Advertising and US alcoholic beverage demand: system-wide estimates. Appl. Econ. 27, 1225-1236.

Robert, J., Stahl, D.O. II, 1993. Informative price advertising in a sequential search model. Econometrica 61, 657-686.

Rosenthal, R., 1980. A model in which an increase in the number of sellers leads to a higher price. Econometrica 48, 1575-1579.

Roy, S., 1998. Strategic segmentation of a market. Int. J. Ind. Organ. 18, 1270-1290.

Scherer, F. M. , Ross, D. , 1990. Industrial Market Structure and Economic Performance. Houghton Mifflin Co., Boston.

Schmalensee, R., 1976. A model of promotional competition in oligopoly. Rev. Econ. Stud. 43, 493-507.

Stahl, D.O. II, 1989. Oligopolistic pricing with sequential consumer search. Amer. Econ. Rev. $79,700-712$.

Stigler, G.L., 1961. The economics of information. J. Polit. Economy 69, 213-225.

Sutton, J., 1991. Sunk Costs and Market Structure. MIT Press, Cambridge.

Tremblay, V., Polasky, S., 2002. Advertising with subjective horizontal and vertical differentiation. Rev. Ind. Organ. 20, 253-265.

Varian, H., 1980. A model of sales. Amer. Econ. Rev. 70, 651-659.

Vives, X., 1999. Oligopoly Pricing: Old Ideas and New Tools. MIT Press, Cambridge.

von der Fehr, N.-H.M., Stevik, K., 1998. Persuasive advertising and product differentiation. Southern Econ. J. 65, 113-126. 